Sorting out $Q$ values, threshold energies and level excitations in ENDL and ENDF

D. A. Brown

November 3, 2005 
This document was prepared as an account of work sponsored by an agency of the United States Government. Neither the United States Government nor the University of California nor any of their employees, makes any warranty, express or implied, or assumes any legal liability or responsibility for the accuracy, completeness, or usefulness of any information, apparatus, product, or process disclosed, or represents that its use would not infringe privately owned rights. Reference herein to any specific commercial product, process, or service by trade name, trademark, manufacturer, or otherwise, does not necessarily constitute or imply its endorsement, recommendation, or favoring by the United States Government or the University of California. The views and opinions of authors expressed herein do not necessarily state or reflect those of the United States Government or the University of California, and shall not be used for advertising or product endorsement purposes.

This work was performed under the auspices of the U.S. Department of Energy by University of California, Lawrence Livermore National Laboratory under Contract W-7405-Eng-48. 


\section{Sorting out $Q$ values, threshold energies and level excitations in ENDL and ENDF}

David Brown

27 Oct 2005

While attempting to convert data to/from ENDF and ENDL, I discovered inconsistencies in the treatment of $\mathrm{Q}$ values in ENDF. These are my notes documenting these inconsistencies. The most interesting section is the last section where I compare $\mathrm{Q}$ values in JENDL-3.3 and ENDF/B-VII $\beta 1$ for various Americium isotopes.

\section{General definitions}

Q The $\mathrm{Q}$ value (a.k.a. mass difference $\mathrm{Q}$ value). Defined in terms of the initial and final masses as $\mathrm{Q}=\left[\left(\mathrm{m}_{\mathrm{a}}+\mathrm{m}_{\mathrm{A}}\right)-\left(\mathrm{m}_{\mathrm{b}}+\mathrm{m}_{\mathrm{c}}+\ldots+\mathrm{m}_{\mathrm{B}}\right)\right]$.

$\mathrm{E}_{\text {threshold }}$ The threshold energy of the reaction. From a consideration of momentum and energy conservation for the reaction, one can show that it should be $\mathrm{E}_{\text {threshold }}=$ $-\left(\mathrm{m}_{\mathrm{a}}+\mathrm{m}_{\mathrm{A}}\right) * \mathrm{Q} / \mathrm{m}_{\mathrm{A}}$.

$\mathrm{E}_{\text {target }} \quad$ The excitation level of the target of the reaction.

$\mathrm{E}_{\text {product }}$ The excitation level of the product nucleus of the reaction.

\section{ENDL Rules}

ENDL rules are very straightforward. There are three fields that more or less determine everything, although one field (X1) has meaning that depends on the ENDL S number. In the first row of the header of each file, one specifies the ELEVEL which is the excitation level of the target, $\mathrm{E}_{\text {target. }}$ This is how one specifies an isomer target in ENDL. On the second line of the header, we write the $\mathrm{Q}$ value for the ground state. We do this whether or not the target is actually in the ground state. Finally, for $S=1$ data, the X1 field of the second line of the header caries the excitation level of the product, $\mathrm{E}_{\text {product. }}$ The energies of all of these fields are given in $\mathrm{MeV}$.

\section{ENDF Rules}

For ENDF, the situation is very different and quite complicated. Rather than list the rules here, I will attempt to quote from the relevant sections from the ENDF-6 Formats and Procedures Manual (ENDF-102) wherever possible.

\section{III.A. From the General Information section (MT 451, MF 1):}

In this section, there is only one relevant piece of information, namely the definition of the excitation energy of the target $\mathrm{E}_{\text {target. }}$ This is given in the ELIS field of the header. The only guidance on this is in the table of parameters in the header:

ELIS Excitation energy of the target nucleus relative to 0.0 for the ground state. 


\section{III.B. From the cross section documentation (MF 3):}

In this section, the rules for stating the $\mathrm{Q}$ value and $\mathrm{E}_{\text {product }}$ and their interaction with $\mathrm{E}_{\text {threshold }}$ are quite complex. Below is a list of the relevant parameters in the data header:

QM Mass-difference Q value $(\mathrm{eV})$ : defined as the mass of the target and projectile minus the mass of the residual nucleus in the ground state and masses of all other reaction products; that is, for $a+A \rightarrow b+c+\ldots+B, Q M=\left[\left(m_{a}+m_{A}\right)-\right.$ $\left.\left(\mathrm{m}_{\mathrm{b}}+\mathrm{m}_{\mathrm{c}}+\ldots+\mathrm{m}_{\mathrm{B}}\right)\right]\left(9.315016 \times 10^{8}\right)$ if the masses are in amu. (See paragraph 3.3.2).

QI Reaction Q value for the (lowest energy) state defined by the given MT value in a simple two-body reaction or a breakup reaction. Defined as QM for the ground state of the residual nucleus (or intermediate system before breakup) minus the energy of the excited level in this system. Use QI=QM for reactions with no intermediate states in the residual nucleus and without complex breakup $(\mathrm{LR}=0)$. (See paragraph 3.3.2.)

Note: the definitions for QM and QI are not grammatically correct so that it is not clear which nuclei must be in the ground state. This may be the origin of the things that I note in section VI. The procedures for specifying these parameters and the threshold energies are given in the procedures section for this file. I will quote directly from them below.

\section{General Procedures for Cross Sections, Energy Ranges, and Thresholds}

For incident neutrons, the cross-section data must cover an energy range up to a common upper limit of at least $20 \mathrm{MeV}$, and the data must extend to a lower limit of the reaction threshold or $10^{-5} \mathrm{eV}$ whichever is higher. For other reactions, the cross section should start at the reaction threshold energy (with a value of 0.0 barns) and should continue up to a common upper energy limit.

For charged-particle emission, the cross section is usually very small from the threshold (or lower limit) up to an effective threshold defined by a noticeable cross section (for example, $10^{-10}$ barns). The evaluator should tabulate a cross section of 0.0 in such a range in order to avoid interpolation problems.

Sometimes ENDF reactions have an apparent upper limit lower than the upper limit for the material due to changes in representation in different sections. For example, there might be a change from discrete levels to a continuum rule, or from separate reactions to $\mathrm{MT}=5$. Such cross sections must be double valued at the highest energy for which the cross section is nonzero. The second cross section at the discontinuity must be zero, and it must be followed by another zero value at the upper limit. This will positively show that the cross section has been truncated. For such reactions, there will be another 
reaction with an artificial threshold at the discontinuity. The cross sections must be chosen in such a way that their sum is continuous.

\section{General Procedures for Q Values (paragraph 3.3.2)}

Accurate $\mathrm{Q}$ values should be given for all reactions, if possible. If $\mathrm{QI}$ is not well defined (as for a range of levels in MT=91, 649, 699, 749, 799, or 849), use the value of QI which corresponds to the threshold of the reaction. Similarly, if the value of QM is not well defined (as in elements or for summation reactions like MT=5), use the value of $\mathrm{QM}$ which gives the threshold. If there is no threshold, use the most positive $\mathrm{Q}$ value of the component reactions. Note that these ill-defined values of QM cannot be relied on for energy-release calculations.

As an example to clarify the use of QM and QI, consider the reaction $a+{ }^{9} \mathrm{Be} \rightarrow \mathrm{n}+\mathrm{X}$. After the neutron has been emitted, the compound system is ${ }^{12} \mathrm{C}$ with $\mathrm{QM}=5.702 \mathrm{MeV}$ and energy levels $\left(E_{x}\right)$ at $0.0,4.439,7.654$, and $9.641 \mathrm{MeV}$. The ground state is stable against particle breakup, the first level decays by photon emission, and the higher levels decay with high probability by breaking up into three alpha particles $(7.275 \mathrm{MeV}$ is required). This pattern can be represented as follows.

\begin{tabular}{|lllll|}
\hline Reaction & QM & QI & EX & MT \\
\hline $9 \mathrm{Be}\left(\mathrm{a}, \mathrm{n}_{0}\right) 12 \mathrm{C}$ & 5.702 & 5.702 & 0.000 & 50 \\
\hline $9 \mathrm{Be}\left(\mathrm{a}, \mathrm{n}_{1}\right) 12 \mathrm{C}$ & 5.702 & 1.263 & 4.439 & 51 \\
\hline $9 \mathrm{Be}\left(\mathrm{a}, \mathrm{n}_{2}\right) 12 \mathrm{C}(3 \alpha)$ & -1.573 & -1.952 & 7.654 & 52 \\
\hline $9 \mathrm{Be}\left(\mathrm{a}, \mathrm{n}_{3}\right) 12 \mathrm{C}(3 \alpha)$ & -1.573 & -3.939 & 9.641 & 53 \\
\hline $9 \mathrm{Be}\left(\mathrm{a}, \mathrm{n}_{\mathrm{C}}\right) 12 \mathrm{C}(3 \alpha)$ & -1.573 & -1.573 & & 91 \\
\hline
\end{tabular}

The gamma for the second reaction is not written explicitly in this notation. The last reaction includes the contributions of all the levels above $9.641 \mathrm{MeV}$, any missed levels, and any direct four-body breakup; therefore, the threshold for MT=91 may be lower than implied by the fourth level of ${ }^{12} \mathrm{C}$. Note the value used for QI.

•.

The $\mathrm{Q}$ value for $\mathrm{MT}=18,19,20,21$, and 38 is the energy released per fission minus the neutrino energy. It should agree with the corresponding value given in $\mathrm{MT}=458$ in File 1.

\section{III.C. From the production cross section data (MF 10):}

LIS Indicator to specify the level number of the target. 
LFS Indicator to specify the level number of the nuclide (ZAP) produced in the reaction (MT) number. $\mathrm{LFS}=0$ the final state is the ground state.

$\mathrm{LFS}=1$ the final state is the first excited state.

LFS $=2$ the final state is the second excited state.

LFS $=98$ an unspecified range of final states.

QM Mass-difference Q value (eV) defined as the mass of the target and projectile minus the mass of the residual nucleus in the ground state and masses of all other reaction products; that is, for $\mathrm{a}+\mathrm{A} \rightarrow \mathrm{b}+\mathrm{c}+\ldots+\mathrm{B}$, if the masses are in amu,

$\mathrm{QM}=\left[\left(\mathrm{m}_{\mathrm{a}}+\mathrm{m}_{\mathrm{A}}\right)-\left(\mathrm{m}_{\mathrm{b}}+\mathrm{m}_{\mathrm{c}}+\ldots+\mathrm{m}_{\mathrm{B}}\right)\right] \times(\mathrm{amu} / \mathrm{eV})$

QI Reaction $\mathrm{Q}$ value $(\mathrm{eV})$ for the state described by the subsection.

For isomeric, states QI is defined as QM minus the residual excitation energy of the isomer.

For the ground state, $\mathrm{QI}=\mathrm{QM}$.

\section{Procedures}

Isomer production cross sections must be given in File 10 for those reactions described in $\mathrm{MF}=8$ which have $\mathrm{LMF}=10$ in the LIST record of the subsection for that particular MT number and value of LFS. The data in File 10 are the cross sections for the production of a final state (LFS) of the daughter product nucleus. For a reaction represented by resonance parameters in File 2, File 10 cannot be used; only multiplicities in File 6 or File 9 are allowed.

The data in File 10 must cover the entire energy range for each reaction from the threshold of the subsection in File 10 up to $20 \mathrm{MeV}$. That is, cross sections cannot be used over a portion of the incident neutron energy range with multiplicities covering another portion. For negative $\mathrm{Q}$ reactions, the first energy point should be at the threshold of the subsection in File 10 and the cross section at this point must be zero. 


\section{Anomalies in treatment of Q values in $242 \mathrm{mAm}$ in ENDF}

\begin{tabular}{|c|c|c|c|c|c|c|c|c|c|}
\hline \multirow[b]{2}{*}{ Reaction } & \multirow[b]{2}{*}{ Target } & \multirow[b]{2}{*}{ Library } & \multicolumn{3}{|c|}{ NuDat Values } & \multicolumn{4}{|c|}{ ENDF File } \\
\hline & & & $\begin{array}{l}\text { Q Value } \\
(\mathrm{MeV})\end{array}$ & $\begin{array}{l}\text { Ethreshold } \\
(\mathrm{MeV})\end{array}$ & $\begin{array}{l}\text { Elevel } \\
(\mathrm{MeV})\end{array}$ & $\begin{array}{l}\text { QM } \\
(\mathrm{MeV})\end{array}$ & $\begin{array}{l}\text { QI } \\
(\mathrm{MeV})\end{array}$ & $\begin{array}{l}\text { Ethreshold } \\
(\mathrm{MeV})\end{array}$ & $\begin{array}{l}\text { ELIS } \\
(\mathrm{MeV})\end{array}$ \\
\hline $\begin{array}{l}(n, g) \\
M T=102\end{array}$ & $241 \mathrm{Am}$ & $\begin{array}{l}\text { ENDF/B-VII } \\
\text { JENDL-3.3 }\end{array}$ & 5.53764 & 0 & $\begin{array}{l}0 \\
0 \\
\end{array}$ & & & & \\
\hline$(n, g)$ & $242 \mathrm{Am}$ & ENDF/B-VII & 6.36489 & 0 & 0 & 6.3671 & 6.3671 & $1.00 \mathrm{E}-11$ & 0 \\
\hline $\mathrm{MT}=102$ & & JENDL-3.3 & & & 0 & 6.3671 & 6.3671 & $1.00 \mathrm{E}-11$ & 0 \\
\hline$\left(n, n^{\prime}\right)$ & $242 \mathrm{Am}$ & ENDF/B-VII & & & 0 & 0 & -0.041 & 0.042838 & 0 \\
\hline $\mathrm{MT}=51$ & & JENDL-3.3 & & & 0 & 0 & -0.041 & 0.042838 & 0 \\
\hline$(n, 2 n)$ & $242 \mathrm{Am}$ & ENDF/B-VII & -5.53764 & 5.560523 & 0 & -5.538 & -5.538 & 5.560688 & 0 \\
\hline $\mathrm{MT}=16$ & & JENDL-3.3 & & & 0 & -5.539 & -5.539 & 5.56208 & 0 \\
\hline$(n, g)$ & $242 \mathrm{mAm}$ & ENDF/B-VII & 6.41349 & 0 & 0.0486 & 6.37 & 6.37 & $1.00 \mathrm{E}-11$ & 0.0486 \\
\hline $\mathrm{MT}=102$ & & JENDL-3.3 & & & 0.0486 & 6.37 & 6.37 & $1.00 \mathrm{E}-11$ & 0.0486 \\
\hline$\left(n, n^{\prime}\right)$ & $242 \mathrm{mAm}$ & ENDF/B-VII & & 0 & 0.0486 & 0.0486 & 0.0486 & $1.00 \mathrm{E}-11$ & 0.0486 \\
\hline $\mathrm{MT}=51$ & & JENDL-3.3 & & & 0.0486 & 0.0486 & 0.0486 & $1.00 \mathrm{E}-11$ & 0.0486 \\
\hline$(n, 2 n)$ & $242 \mathrm{mAm}$ & ENDF/B-VII & -5.48904 & & 0.0486 & -5.49 & -5.49 & $5.51 \mathrm{E}+00$ & 0.0486 \\
\hline$M T=16$ & & JENDL-3.3 & & & 0.0486 & -5.539 & -5.539 & $5.56 \mathrm{E}+00$ & 0.0486 \\
\hline$(n, 2 n)$ & $243 \mathrm{Am}$ & ENDF/B-VII & -6.36489 & 6.39108 & 0 & & & & \\
\hline$M T=16$ & & JENDL-3.3 & & & 0 & & & & \\
\hline & & & $\begin{array}{l}\text { mass } \\
\text { difference } \\
\text { Q value of } \\
\text { actual } \\
\text { projectile }\end{array}$ & & & $\begin{array}{l}\text { Note on } \\
\text { appears } \\
\text { that the } \\
\text { isomer i }\end{array}$ & $\begin{array}{l}\text { the } 242 \mathrm{~m} \\
\text { that JENL } \\
\text { first exci } \\
\text { s the ison }\end{array}$ & $\begin{array}{l}\mathrm{mAm}\left(\mathrm{n}, \mathrm{n}^{\prime}\right) \text { dat } \\
\mathrm{DL} \text { and ENDF/ } \\
\text { ited state of th } \\
\text { mer itself }\end{array}$ & $\begin{array}{l}\text { a: it } \\
\text { B figure } \\
\text { he }\end{array}$ \\
\hline & & & & & & $\begin{array}{l}\text { Note on } \\
\text { they use } \\
\text { state, no } \\
\text { used the } \\
\text { calculati }\end{array}$ & $\begin{array}{l}\text { the } 242 \mathrm{~m} \\
\text { ed the } \mathrm{Q} \\
\text { ot the isol } \\
\text { e isomer } \\
\text { ion. }\end{array}$ & $\begin{array}{l}n A m(n, 2 n): \text { it } \\
\text { values for the } \\
\text { mer, whereas } \\
\text { energy in the }\end{array}$ & $\begin{array}{l}\text { appears } \\
\text { ground } \\
\text { ENDF } \\
\text { Q value }\end{array}$ \\
\hline
\end{tabular}

